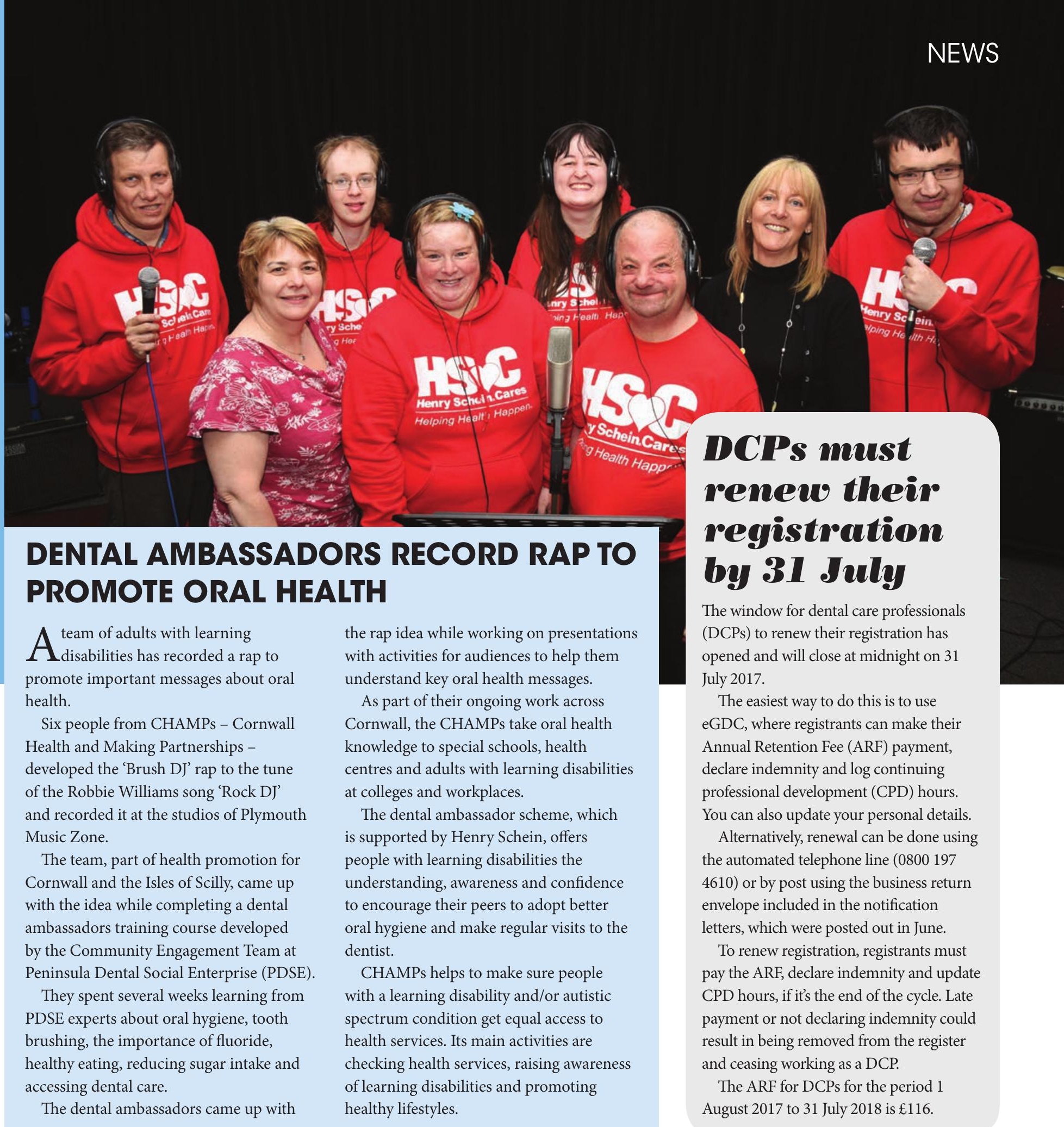

\title{
SCHEME FOSTERS CLOSER LINKS BETWEEN INDUSTRY AND DENTAL NURSES
}

The British Association of Dental Nurses (BADN) is re-launching its Affiliates Scheme, now re-named the Dental Industry Affiliate Scheme.

The Scheme is designed to foster closer links between dental industry companies and dental nurses.

BADN President Jane Dalgarno said: 'Many dental industry companies are still unaware of the vital role of the dental nurse within the dental team. Our Scheme is designed to enlighten those companies on the professionalism and varied responsibilities of the registered dental nurse, and to provide a conduit between dental nurses and dental industry companies.

Dental industry companies participating in the Scheme will have access to the BADN's quarterly digital publication, The British Dental Nurses' Journal, special affiliate advertising rates in the Journal, a company profile on BADN's website www.badn.org.uk with links to their own site, and opportunities to promote their products and special offers through BADN's communication channels. Affiliate companies will also be able to display a Dental Industry Affiliate version of the BADN logo to indicate that they recognise dental nurses as professionals and as valued members of the dental team.

More information on the Scheme, and application forms, are available from the BADN Chief Executive at pam@badn.org.uk. 